\section{Re-evaluating Buchanan's conception of law and law-making}

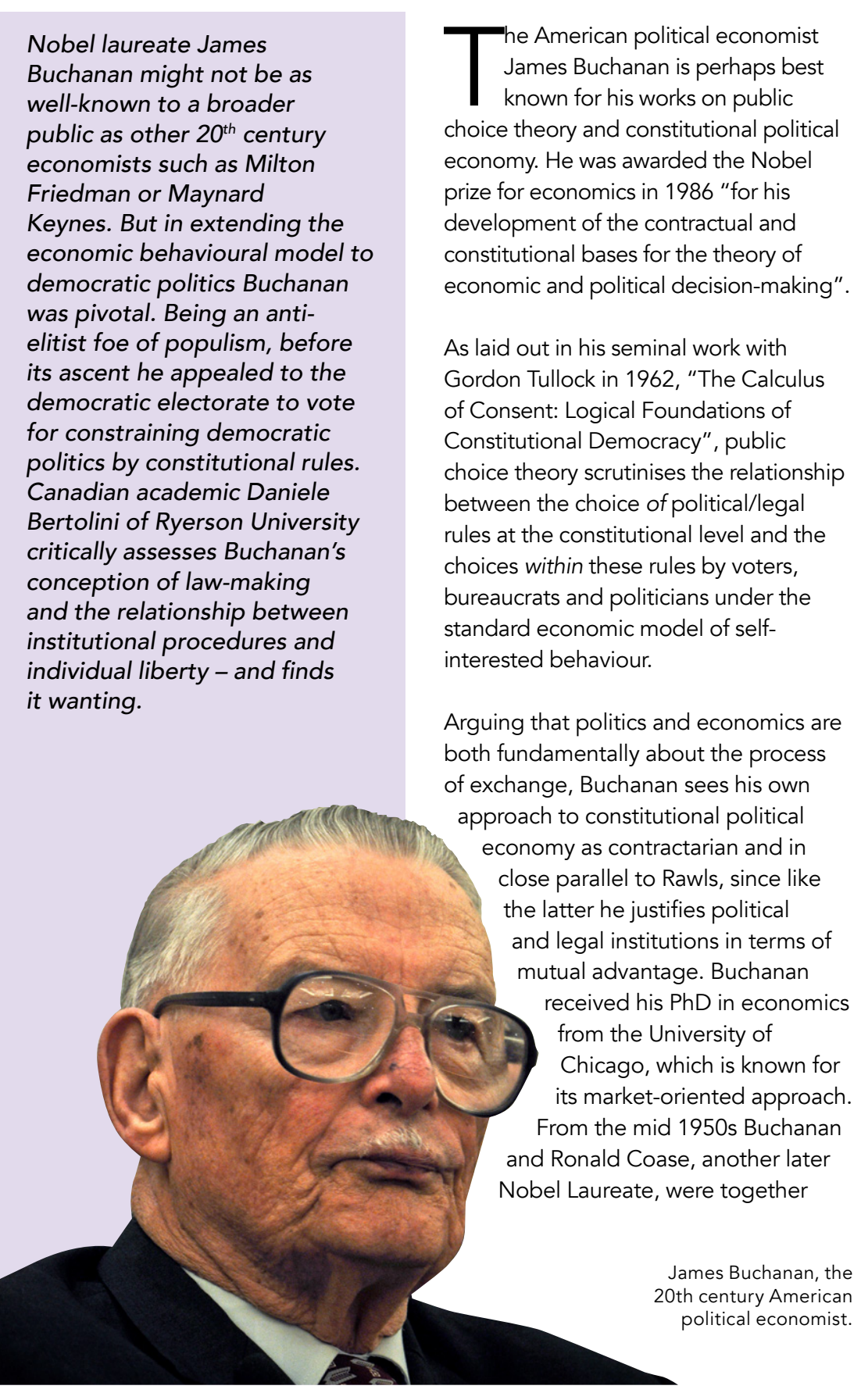

at the University of Virginia laying the foundations of the law and economics ctablished the The Center for Studies in Polticarson Which wortic "Public Choice".

A new generation of academics is reevaluating Buchanan's work. Among them is Daniele Bertolini, Assistant Professor of Law and Business at Ryerson University in Canada. In a recent paper Dr Bertolini presents a critique of Buchanan's conception of law-making and concludes that Buchanan ultimately fails to understand the complex relationship between the law-making process and individual liberty within the

HISTORICAL BACKGROUND Buchanan proposes a social contract teinterprets the id $17^{\text {th }}$ centur English philosopher Thomas Hobbes modern economic terms. Hobbes argued that individuals relinquish their autonomy to the absolute power of the state in exchange for the state protecting them from living in a "lawless state of nature". In his work "Leviathan " Hobbes famously described such a life as "solitary, poor, nasty, brutish, and short".

Hobbes' fellow enlightenment thinker John Locke took a more favourable view of human nature and believed that individuals are equals with innate rights which predate the social contract. He favoured a constitutional government with limited power, on the individual liberties.
Dr Bertolini argues that, by rejecting natural rights, Buchanan understands the social contract in a way that forces him to take sides with the unconstrained political authority conception of Hobbes. Buchanan conceptualises the social contract as the unanimous agreement of all members of the community, which is the necessary and sufficient source of legitimate constitutional law. In this way, Buchanan endows the collectivity of all citizens with unconstrained law-making pow and the social contract becomes the legitimising source of a substantively unconstrained law-making mechanis

THE ARGUMENT

Dr Bertolini examines Buchanan's

conception of law-making, with a focus to promote individual liberty. He argues that Buchanan's assumptions concerning the sources of law and the law-making process limit the theoretical strength of his constitutional framework and undermine the effectiveness of the legal and institutional measures he proposes to protect individual liberty against political intrusion.

Dr Bertolini's critique centres on his belief that Buchanan's conception of law-making affords merely formal (procedural) constraints on the lawmaking activity conducted by politicicins and ultimately fails to provide a satisfactory nomative account of the making process and individual liberty within the constitutional order".

Dr Bertolini raises four specific criticisms in support of his thesis:

That Buchanan is unable to justify the foundations of the legal order;
That he fails to appreciate the 2. That he fails to appreciate the distinction between constitutional principles and constitutional rules That his commitment to legal
generality (that laws apply to generality (that laws apply to everyone equally) is an ineffectua institutional promoter of liberty; . And that his approach to law-making leaves no rom for the mer judicial process.

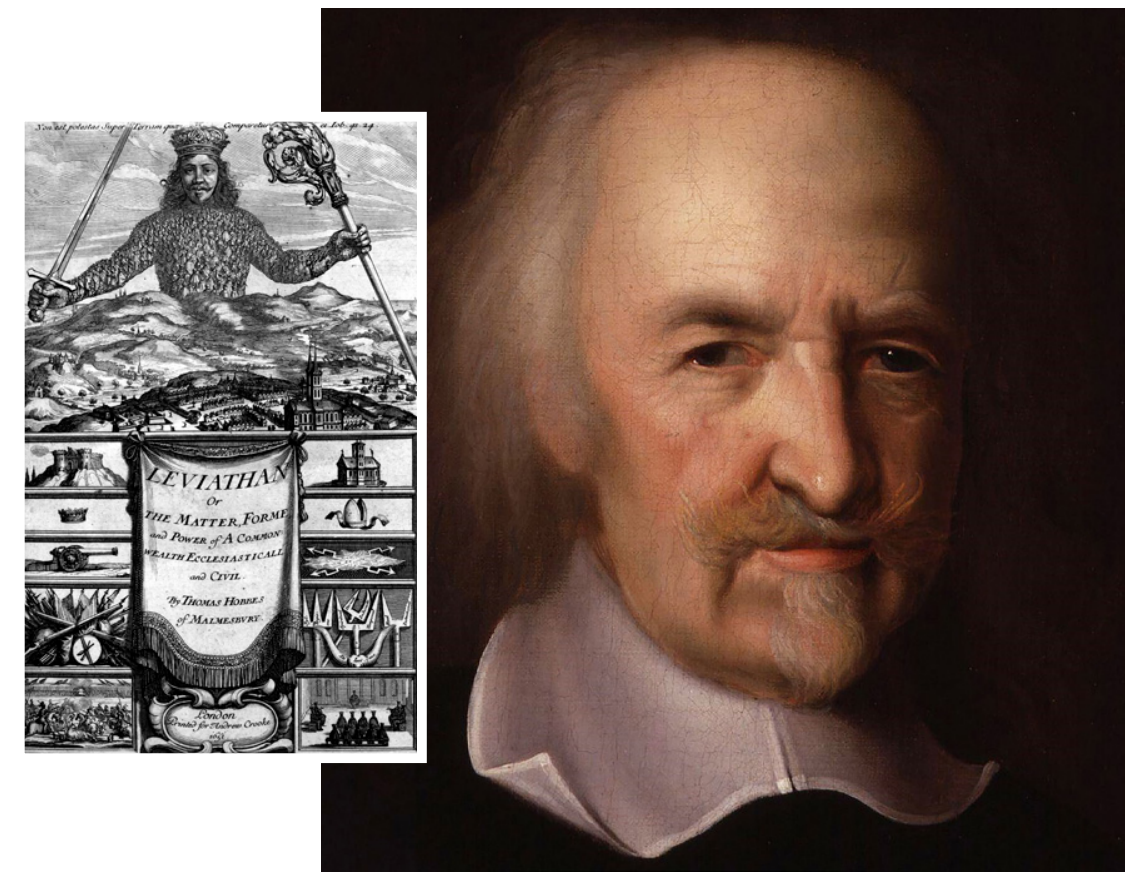

Buchanan understands the social contract to mean that political powers have exclusive authority to make the law.

FOUNDATION OF LEGAL ORDER In some important respects, Buchanan 's conception of law-making resembles that of the influential $20^{\text {th }}$ century Austrian legal philosopher Hans Kelsen who argued that questions of law are questions of fact. Any substantive

Dr Bertolini argues that, by assuming of fact, enacted according to the basic a fundamental norm that requires

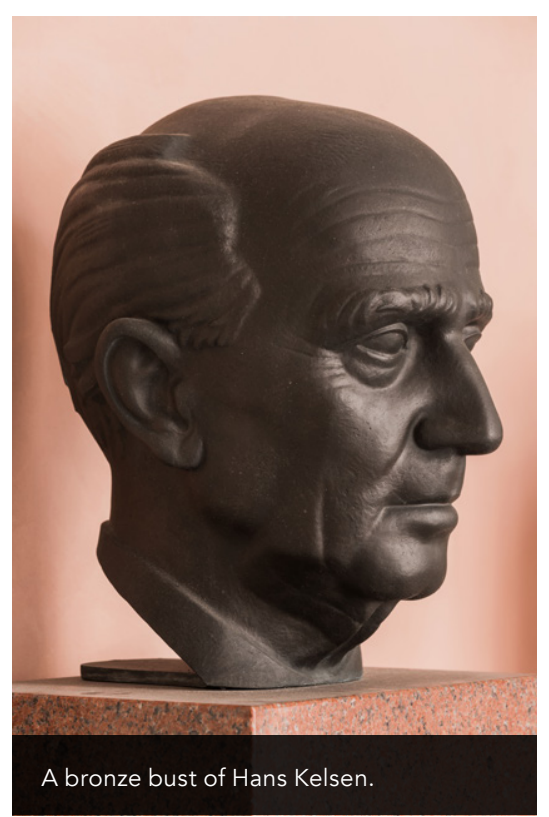
( of Kelsenian legal positivism. In Dr Bertolini's words: "Kelsen's assumption of the existence of a basic norm conferring validity to the legal order is as difficult to justify as Buchanan's assumption of an original contract. preceding all social institutions. This way, Buchanan's legal formalism is unable to provide a solid jurisprudential grou upon which effective institutional promoters of liberty can be established."

Crucially, by assuming that the unanimity principle is the only limitation to the social contract, Buchanan ultimately fails to efectively constrain the lawmaking authority of political law-makers t the post-constitutional stage of the 


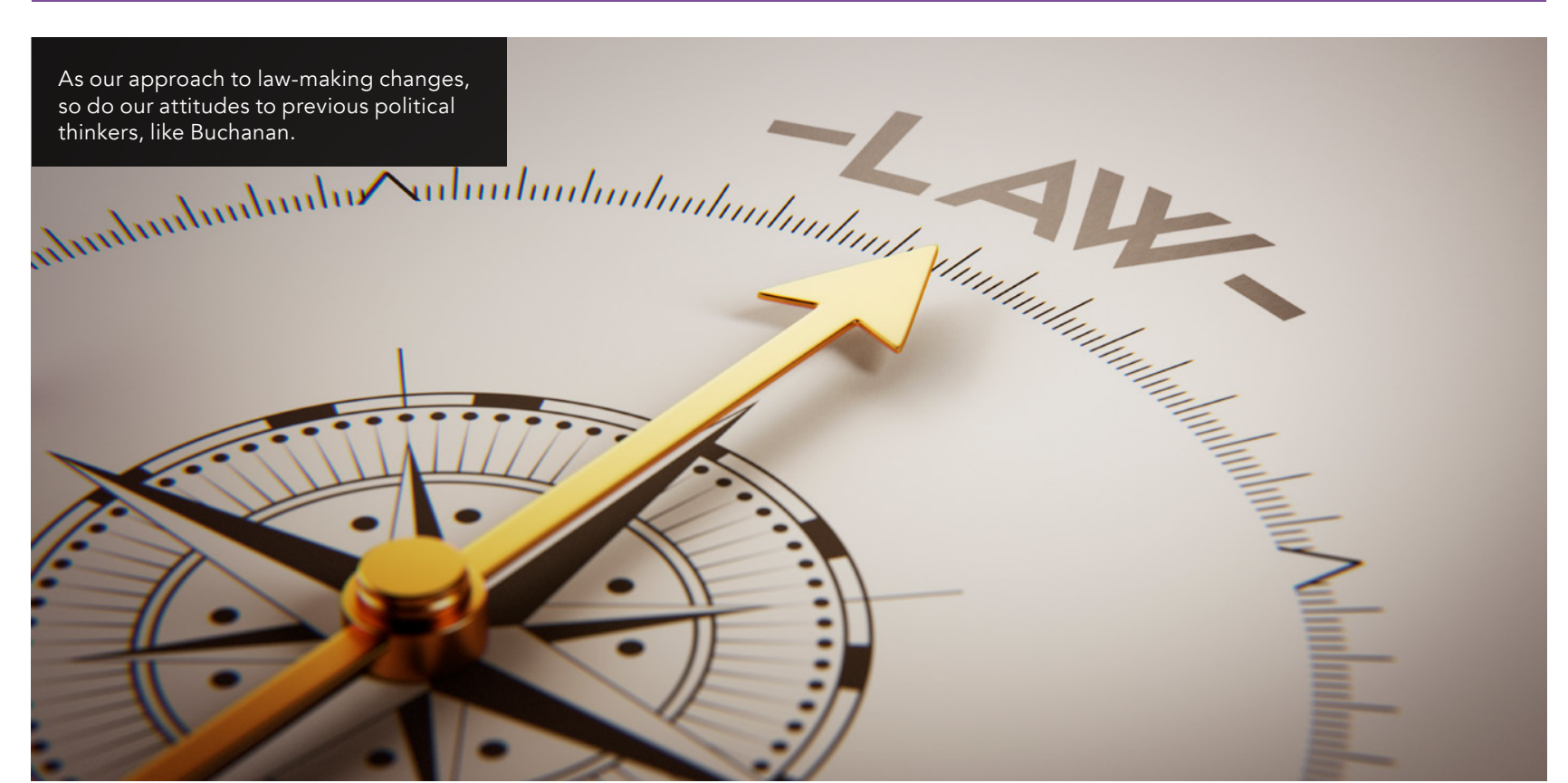

\section{PRINCIPLES AND RULES}

Dr Bertolini argues that Buchanan

the distinction between constitution

principles and constitutional rules.

He explains: "Buchanan distinguishes

between choice of rules (which must be agreed unanimously) and choice made within those rules (which are made by politicians under majority rule). In this way he assumes that constitutional rules are apt to provide clear, well-defined constraints on the post-constitution exercise of legislative power."

In practice, however, constitutiona principles are not so clear-cut and demand considerable interpretation
by those with by those with responsibility for

subsequently

enacting

constitutional

rules. Dr

Bertolini adds: "This suggests that when principles are chosen, a post constitutional actor (e.g., Parliament) chooses the substantive rule without the consent of the individuals affected by the choice."

\section{LEGAL GENERALITY}

Buchanan proposes that the generality of law, which is equally applicable to all members of society, protects individ liberty from coercive government intrusion inco the pivate sphere. In

making laws that apply selectively to specific people or groups.

However, Buchanan's commitment to legal generality fails as an effective institutional promoter of liberty. As Dr Bertolini explains: "Generality requires the lawmaker to provide equal legal treatment to all persons who belong categorizing people involves ethica judgements (clarifying 'in what respec' people must be equal) that Buchanan's ethical subjectivism does not permit."

This further reinforces the argument that "Buchanan's constitutional framework is to capture the institutional heterogeneity procedural in nature and cannot provide He also falls to see that "the protection
Buchanan fails to capture the institutional heterogeneity of the sometimes from judges or from a private legal orders that is law made by that is law made by
private parties". For instance, political powers to initiate restrictions of liberty by means of centralised law-making are limited to the extent that private individuals must useful indications on the choice of the elements on the basis of which people

EVOLUTIONARY JUDICIAL PROCESS go to court to initiate a decentralised Dr Bertolini raises concerns about "common law-making" process. Buchanan's implicit assumption that good that can only be created through collective decision-making processes" Such a sovereign-centred approach to law-making leaves no room for the evolutionary judicial process. Dr Bertolin

IN CONCLUSION

Dr Bertolinis robust critique of of the work of this highe re-evaluation of the work of this highly influential thinker and Nobel prize winner. law is a fixed and "indivisible public

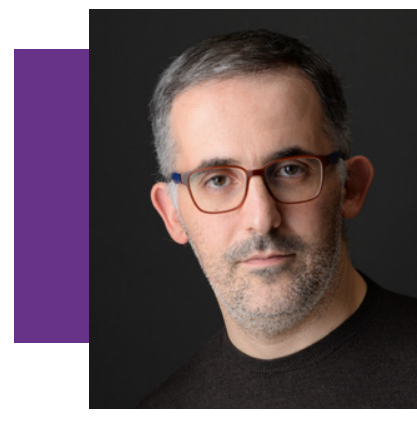

\section{Behind the Research}

\section{Dr Daniele Bertolini}

E: daniele.bertolini@ryerson.ca T: +1 416-979-5000 ext: 3606

W: https://www.ryerson.ca/tedrogersschool/bm/programs/law-business/daniele-bertolini/

explains: "Buchanan's formalist and rigid of the law-making processes He neglects the role that judges and spontaneous orders can play in effectively promoting individual liberty."

By focusing solely on protecting liberty through a constitutional order that has been unanimously approved, Buchanan fails to acknowledge the role of alternative safeguards for liberty. More specifically, Buchanan fails to "fully appreciate the comparative advantages of decentralized, evolutionary, legal He also fais to see that "the of liberty".

\section{Research Objectives}

Dr Bertolini interrogates Buchanan's conception of law and lawmaking.

\section{Detail}

Daniele Bertolini

Nagement - Ryerson University Mailing Address:

350 Victoria Street,

Toronto, Ontario,

M5B 2K3

Bio

Daniele Bertolini is an Assistant Professor at the Law \& Business Department, Ted Rogers School of Management, Ryerson University. He joined the Ted Rogers School of Management in August 2015. His research agenda focuses on issues concerning the analysis of alternative law making processes. Buchanan's approach to law-making is a

\section{References}

Bertolini, D. (2019). Constitutionalizing 'Leviathan : a critique of Buchanan's conception of lawmaking. Homo Oeconomicus: Journal of Behavioral and Institutional https://doi.org/10.1007/s41412-019-00086-5

\section{Personal Response}

How big a threat does Buchanan's thinking pose to the protection of individual liberties in Western democracies in the $2 \mathbf{1}^{\text {st }}$ century?

II Despite its genuine commitment to the ideal of complexity of the relationship between law-making and freedom in contemporary constitutional orders and misses the goal of identifying effective institutional promoters of liberty. From a broader perspective, political order reflects the increasing difficulties of classical liberalism to explain the fragilities of current constitutional democracies and to understand the growing legitimacy crisis of political democratic
institutions around the world. 